https://doi.org/10.52505/filomod.2021.15.36

\title{
FORMULE DENOMINATIVE CREATE DE LA PRENUME MASCULINE
}

\author{
VIORICA RĂILEANU \\ Institutul de Filologie Română „B. P.-Hasdeu” al MEC
}

\begin{abstract}
Rezumat. Formula oficială de denominație a unei persoane conține două elemente: prenumele şi numele de familie. Această formulă denominativă $s-a$ oficializat abia la sfârșitul secolului al XIX-lea. Anterior, pentru identificarea și individualizarea persoanelor s-a folosit denominația cu nume unic, având la bază un nume de botez. Când numele unic nu a mai reușit să-și îndeplinească rolul de identificare, s-a adăugat un nume complementar, folosit, la început, ocazional. Reconfigurarea formulei antroponimice a dezvoltat o tipologie a supranumelor care indicau descendența personală, descendența locală, etnia, ocupația etc. Numeroase supranume cu descendență personală au la origine prenume masculine, care se prezintă astăzi ca nume de familie.
\end{abstract}

Cuvinte-cheie: nume unic, nume complementar, nume de familie, formulă denominativă, prenume masculin, sistem antroponimic.

Abstract. The official name formula for naming a person contains two elements: first name and last name. This denominative formula was made official only at the end of the 19th century. Previously, for the identification and individualization of people, the denomination with unique name was used, based on a baptismal name. When the unique name failed to fulfill its identifying role, a complementary name was added, used occasionally at first. The reconfiguration of the anthroponymic formula developed a typology of surnames that indicated personal descent, local descent, ethnicity, occupation, etc. Many surnames with personal descendants originate from male first names, that are presented today as family names.

Keywords: unique name, complementary name, family name, denominative formula, masculine first name, anthroponymic system.

Structura pe care o are astăzi antroponimia românească se datorează unor îndelungate procese de dezvoltare, procese de sedimentări succesive care au fost determinate de mai mulți factori lingvistici și extralingvistici.

Pe perioade întinse de timp nu avem înregistrate legi scrise privitor la numele de persoană. A existat însă „obiceiul pământului”, „legea țării”, norme populare de factură juridică (Vulcănescu, 1970, p. 48), puse în evidență în studiile de antroponimie și, datorită cărora, avem o mai bună înțelegere a particularităților sistemului de denominație a persoanelor. Aflăm, astfel, că pentru persoane s-a folosit, pentru început, denominația cu nume unic, alcătuit dintr-un nume de botez (religios sau laic), prenumele de astăzi. „Vechimea 
acestora în limbă poate fi urmărită de-a lungul etapelor de dezvoltare a limbii române, de la începuturile ei până în prezent.” (Oancă, 2016, p. 7)

Când numele unic nu mai reușea să-și îndeplinească rolul de identificare și individualizare, apare denominația dublă/ mixtă, având în structură un nume de botez (cu funcție de prenume) şi un nume complementar (cu funcție de nume de familie), care se folosea, la început, ocazional. Când ,se cerea o precizie ceva mai mare, se adăuga numele tatălui sau al soțului, câteodată al mamei sau al soției, în genitiv: Ion al lui Gheorghe, Niculaie al Saftei, Maria lui Vasile." (Graur, 1965, p. 89) Odată cu schimbarea configurației formulei antroponimice, se dezvoltă o tipologie a denominației cu supranume, comună pentru cele trei provincii istorice românești. După marca cutumiară, putem distinge supranume patronimice, matronimice, adelfonimice sau supranume care indicau etnia, descendența locală, ocupaţia etc. „În Ţara Românească, apariţia numelor duble datează din 1387: Dimitrie Dăbăcescul din Dăbăcești, iar în Moldova - din 1393: Dragomir Albu." (Avram et al., 2001, p. 49-50.)

Fixarea numelui dublu s-a generalizat în secolul al XIX-lea, când, în baza unor legi scrise, se impune obligativitatea „numelui patronimic” (de familie) care „constituie un drept imprescriptibil și inalienabil”, configurându-se, astfel, și conceptul de nume de familie. Or, la o lectură atentă a Codului Civil (1864), găsim elemente juridice referitoare la nume și impunea ca, în actele de stare civilă, persoanele să fie arătate prin nume și prenume: „Actul de naştere va arăta cu deslușire ziua, ora, locul nașterii, sexul copilului, prenumele ce i se va da la botez, precum și numele de familie, profesiunea sau meseria și domiciliul tatălui, mamei și a martorilor." Primul act normativ care reglementează într-un tot unitar problemele referitoare la numele persoanei fizice este Legea asupra numelui, nr. 18 din martie 1895, care prevedea: „Locuitorii români, săteni, cari nu au nume patronic (...), își vor putea forma unul cu numele de botez al tatălui lor, adăugându-i una din terminațiunile care sunt în datina țării, cum ar fi escu sau eanu, de natură a diferenția numele de prenume." (Reforma)

De cele mai multe ori, afirmă Mircea Ciubotaru, „stabilirea unui al doilea nume este rezultatul unei improvizații a celor care întocmeau listele de locuitori și nu al unei opțiuni personale (decât, poate, în rare cazuri). Prin copierea succesivă a listelor, numele era acceptat de individ și de comunitate, impus și apoi oficializat în a doua jumătate a secolului al XIX-lea, în etapa eliberării actelor individuale de identitate. Introducerea învăţământului primar general și a serviciului militar obligatoriu a accelerat finalizarea acestui proces prin atribuirea unui nume de familie copiilor și tinerilor care nu aveau decât nume individual." (Cibotaru, 2003, p. 159)

Numele atribuite erau înregistrate de către funcționari în diverse recensăminte și liste, până atunci acest rol le revenea slujitorilor bisericilor (Graur, 1965, 47). Folosirea formulei denominative duble, în tradiția scrisă, creează premise pentru apariția numelui de familie, proces care durează până în secolul al XX-lea. „Chiar dacă oficializarea numelui de familie se face 
mai târziu, caracterul ereditar al supranumelui, impunerea supranumelui în denominația tuturor membrilor familiei respective, prezența supranumelui pe lângă prenume în poziția a doua a formulei denominative mixte/ duble sunt indicii că numele de familie începe să funcționeze." (Tomescu, 2001, p. 77-78)

Numele de familie sunt rezultatul evoluției societătii din ultimele două secole și, în opinia lingvistului Iorgu Iordan, ,nu prezintă dificultăți în ce privește găsirea originii lor. Extrem de numeroase sunt prenume, adică nume de botez sau nume mici, cum li se mai spune, existente în literatura religioasă, devenite nume de familie fără nicio modificare sau primind un sufix." (Iordan, 1983, p. 6)

In antroponimia basarabeană atestăm un număr considerabil de prenume masculine devenite nume de familie: Adam, Albescu, Alexandrescu, Angheleanu, Aroneanu, Dumitru, Demostene, Filip, Gheorghe, Ilie, Ion, Iosif, Iacob, Ignat, Isaia, Iochim, Năstăsache, Nestor, Panait, Severin, Simion, Serafim, Tudor, Toma etc., lucru explicabil prin rolul pe care îl avea bărbatul în familie, or, ,în regulă generală, atât numele comun neamului, cât și individul față de care se arată o aparținere, este ales pe linia descendenței bărbătești." (Paşca, 1936, p. 74)

Denominarea complementară cu un prenume masculin a unei persoane marca cutumiar diferite situații juridice relative: stabilirea raportului de filiaţie, exprimarea apartenenței la un neam, redarea legăturii de rudenie al descendenților „cu forme derivate prin sufixe specializate sau cu forme flexionate" (Tomescu, 2001, p. 75).

Un mijloc de formare a supranumelui de la prenume masculine, păstrat şi azi în graiul popular, presupunea adăugarea la numele unic al persoanei a prenumelui tatălui, soțului, fratelui, socrului, al unui strămoș mai îndepărtat, în formă de genitiv singular, redat în mai multe feluri:

prenume + articol genitival $\boldsymbol{a} / \boldsymbol{a l}+$ prenume: Gheorghie a Tomii (MEF, 1975, p. 424), Grigore a Savii (ibidem, p. 450), Moisăiu a Stratului (ibidem, p. 455). etc.

prenume + articol genitival $a / a l+$ articol proclitic $l u i+$ prenume: Constandin a lui Pintilei (ibidem, p. 458), Ilie a lui Stratulat, Paraschiva a lui Gavril (ibidem, p. 471), Ioniță a lui Ermurachi, Vârlan al lui Alexii (ibidem, p. 472) etc.

prenume + prenume (în genitiv): Darii Mărdarii ( = Darii al lui Mărdarie) (ibidem, p. 424), Niță Măcarii ( = Niță al lui Măcarie) (ibidem, p. 427) etc.

Uneori, pentru a fi evitată coincidența, se adăugau până la trei-patrucinci nume în genitiv: Hiru a lui Nica a Marinii, Neofitu Nichii Ghichii Oanii (Stahl, 1934, p. 83-95) etc.

Un alt mijloc de formare a supranumelui de la prenume masculine a fost adăugarea la numele unic al persoanei a prenumelui patern, însoţit de termenul slav $\sin (\sin )$,fiu”, prepus sau postpus. Or, numele tatălui însoţit de cuvântul „fiu”, cu funcţie de nume de familie, se întâlneşte la diferite popoare şi în diferite perioade. Astfel, în formula latină se scria: filius (Publius Cornelius, 
Cnaei filius (fiul lui Cnaeus), în turcește -oglu (Cristioglu), în germană -sohn (Natansohn), în engleză -son (Robinson), în daneză -sen (Andersen), în slavă -sîn (Бориско Олексъевъ сынъ, Данила Ивановъ сынъ) ${ }^{1}$. În limba română, astfel de formule denominative se atestă începând cu secolul al XVII-lea, sub influența modelului slav.

prenume + $\sin (\boldsymbol{s i n})+$ prenume: Ștefan sin Duțul (MEF, 1975, p. 400), Gavril sîn Sofronii (ibidem, p. 402), Toma sîn Iacob, Andrii sîn Năstasă (ibidem, p. 407), Ioniță sin Luca (ibidem, p. 428), Chiriac sîn Ursul (ibidem, p. 442), Cozma sîn Irimiei (ibidem, p. 472) etc.

Prin deducere, numele de familie atestat astăzi Sînchetru (cu variantele: Sînchetriu, Sinchetru, Senchetru, Simpetru), este un rezultat al contopirii lui sîn „fiu” + Chetru (forma populară a lui Petru) și înseamnă „fiul lui Petru” (cf. Sîntoader).

Alteori prenumele masculin, adăugat la numele unic al persoanei, era însoțit de termenii brat „frate”, zet (zăt) „ginere”. Acești termeni se foloseau în cazurile în care tatăl decedase, iar mijlocul de identificare a individului era „raportarea la alt membru al familiei, acesta fiind un frate mai mar; sau, pentru cel care venea din altă localitate, prin căsătorie, persoana cunoscută la care să se facă trimitere era socrul, deci calitatea de ginere al cuiva era și ea în măsură să-1 identifice." (Oancă, 2001, p. 15)

Cele mai reprezentative formule denominative sunt:

prenume + brat + prenume: Ilie brat Trohin, Ioniță brat Vasile (MEF, 1975, p. 403), Vasie brat Enachi (ibidem, p. 424), Toader brat Lupului (ibidem, p. 438) etc.

prenume + brat + articol proclitic lui + prenume: Apostu brat lui Niță, Irimie brat lui Ion (ibidem, p. 404), Ioniță, brat lui Constandin, Vasîle brat lui Andrei, Hilip brat lui Nistor (ibidem, p. 419) etc.

prenume + zet (zăat) + prenume: Andrii zet Carp (ibidem, p. 431), Ioniță zet Paladi (ibidem, p. 443), Leonte zăt Mitrofan (ibidem, p. 414), Sâmion zăt Sâmion (ibidem, p. 425) etc.

prenume + zet $(z \breve{a} t)+$ articol proclitic lui + prenume: Toader zăt lui Gratii (ibidem, p. 404), Ion zăt lui Vasile (ibidem, p. 423), Tudosâi zăt lui Pahomi (ibidem, p. 466) etc.

Ca semn de apartenență a unei persoane, alături de termenii slavi sin, brat, zet se foloseau și termenii latini nepot, cumnat, fecior, frate:

prenume + nepot + prenume: Gheorghiță nepot Onii (ibidem, p. 402), Toader nepot Guciului (ibidem, p. 424) etc.

prenume + nepot + articol proclitic lui + prenume: Ion nepot lui Vuluță (ibidem, p. 403), Trohin nepot lui Darie (ibidem, p. 415), Irimie nepot lui Trohin (ibidem, p. 425) etc.

prenume + cumnat + prenume: Antohi cumnat Ursului (ibidem, p. 441) etc. 
prenume + cumnat + articol proclitic lui + prenume: Ioniță cumnat lui Agachi (ibidem, p. 416), Irimie cumnat lui Iosip (ibidem, p. 428), Ioniță cumnat lui Carp (ibidem, p. 441) etc. p. 431) etc.

prenume + fecior+ prenume: Săbieriul ficior Tomii (ibidem,

Constatăm, astfel, că pentru stabilirea filiației directe, descendența se arăta prin adăugarea articolului genitival $a / a l$, articolului proclitic lui, prenumelui în genitiv sau prin adăugarea termenilor de rudenie (sîn, brat, zet, nepot, fecior, frate) etc.

Interesant este că termenii sîn, brat, zet, nepot, fecior, frate au avut o evoluție în timp și din simple „,instrumente auxiliare” au devenit nume de familie și se regăsesc în nomenclatura oficială actuală, având următoarele frecvențe: Sin - 138 (cu variantele: Sîncu - 113, Sinco - 29), Bratu - 549 (cu variantele: Bratescu-52, Bratcu-27, Bratoi- 18 etc.), Zeti-26 (cu variantele: Zetea-20, Zetia-6), Nepotu-300, Frate-13, Fecioru -6 etc.

Variantele exprimate prin formule denominative analitice sunt specifice sistemului antroponimic popular și au anticipat variantele în care ambele prenume, al persoanei identificate și al tatălui, se află în nominativ:

prenume + prenume: Vasili Antohi, Ștefan Zaharie, Afteni Pantiul, Irimie Timofte (ibidem, p. 400), Ioniță Timofti, Chiriac Sârghie, Agachii Andrieș, State Tudor, Sandul Filip, Lupul Irimie (ibidem, p. 401), Mafteiu Frimu, Toader Mavrodin (ibidem, p. 403), Sâmion Mitre (ibidem, p. 404), Sandul Pârvul (ibidem, p. 445) etc. Din câte se poate observa, acest tipar denominativ ,trimite la două prenume, primul fiind al persoanei numite și al doilea, prenumele tatălui. Ca urmare, din punct de vedere semantic, ambele admit aceeași analiză, dar, din punct de vedere funcțional, ele se specializează, primul păstrându-și valoarea inițială de nume individual, numit acum prenume, iar al doilea, ca nume al tatălui, comun pentru toți descendenții familiei, este numit nume (de familie). În felul acesta, sintagma prenume + nume capătă statut de formulă antroponimică, păstrându-și valoarea intactă până în zilele noastre" (Ganea, 2017, p. 157-164)

Supranumele care la origine indicau descendența dintr-un prenume masculin se prezintă atât ca nume de familie primare (nederivate), cât și derivate, a căror sferă se lărgește la hipocoristice și diminutivale.

Nume de familie provenite de la prenume masculine nederivate este una dintre cele mai reprezentative categorii, evidențiindu-se prin numărul mare de purtători. Raportate la frecvență, predomină numele de familie care au la origine prenume masculine întâlnite în literatura religioasă: Andrei, Constantin, Dumitru, Gheorghe, Grigore, Ilie, Mihai, Ştefan, Vasile, Zaharia, în defavoarea numelor laice, de creație românească sau împrumutate de la vecini: Dragomir, Florea, Radu, Şerban etc. 
Din punct de vedere morfologic, numele de familie primare coincid prin structură cu cea a prenumelor oficiale: Adam 2366/ Adam $412^{2}$, Andrei 290/ Andrei 72458, Anton 1708/ Anton 4382, Constantin 453/ Constantin 28628, Dumitru 141/ Dumitru 36236, Dragomir 110/ Dragomir 314, Filip 1438/ Filip 1570, Florea 5186/ Florea 79, Gheorghe 52/ Gheorghe 41866, Grigore 146/ Grigore 16616, Ilie 64/ Ilie 9501, Ion 28/ Ion 104041, Isac 2072/Isac 79, Luca 4600/ Luca 1888, Mihai 1454/ Mihai 7644, Nicolae 21/ Nicolae 45284, Pavel 537/ Pavel 20378, Petru 2/ Petru 25218, Platon 3027/ Platon 287, Radu 3622/ Radu 7574, Simion 603/ Simion 5326, Ștefan 441/ Ștefan 11192, Teodor 46/ Teodor 3975, Tudor 635/ Tudor 14002, Vasile 52/ Vasile 52992, Zaharia 2678/ Zaharia 523 etc.; populare: Ioan 10/Ioan 664, Toader 36/ Toader 162 etc; hipocoristice: Chiru 119/ Chiru 2, Dinu 379/ Dinu 1468, Nicu 478/ Nicu 1211, Sandu 5149/ Sandu 1398, Spiru 3/ Spiru 2, Tănase 342/ Tănase 2 etc.

Unele prenume masculine au fost mai productive în derivarea numelor de familie, altele - mai puțin productive. Un rol important, în acest sens, îl joacă vechimea, frecvența, răspândirea prenumelui.

Astfel, inventarul antroponimic, constituit în rezultatul unei îndelungate evoluții istorice, s-a amplificat cu un număr considerabil nume de familie datorită supranumelor cu descendență personală, care au la origine un prenume masculin. Această categorie de nume de familie se impune drept una dintre cele mai reprezentative și se evidențiază prin numărul mare de purtători.

\section{Referințe bibliografice:}

1. AVRAM, Mioara, BALACCIU-MATEI, Jana, FISCHER, I., GHEȚIE, Ion et. al. Enciclopedia Limbii Române. Academia Română, Institutul de Lingvistică „Iorgu Iordan”. București: Editura Univers Enciclopedic, 2001.

2. CIBOTARU, Mircea. Teme de antroponimie istorică. În: Comuna Vulturești. Vol. I. Studiu de istorie socială. Onomastică. Iași: Casa Editorială Demiurg, 2003.

3. Codul Civil, $1864=$ Codul Civil din 1864 [online] Disponibil: https://lege5.ro/ Gratuit/g42tgnry/codul-civil-din-1864 [citat: 25.05.2021].

4. DAUZAT, Albert. Les noms de personnes. Paris, 1928.

5. GANEA, Vali Nastasia, Sacru și profan în sistemul numelor de familie de pe Valea Sălăuței, 2017, p. 157-164. [online] Disponibil: http://onomasticafelecan.ro/iconn4/ proceedings/2_9_Ganea_Vali_Nastasia_ICONN_4.pdf) DOI: 10.30816/ICONN4/2017112 [citat 4.04.20 $\overline{2} 1 \overline{1}$.

6. GRAUR, Alexandru. Nume de persoane. București: Editura Științifică, 1965.

7. IORDAN, Iorgu. Dicţionar al numelor de familie româneşti. Bucureşti: Editura Ştiinţifică şi Enciclopedică, 1983.

8. LEBEL, Paul. Les noms de personnes. Paris, 1959.

9. MEF, 1975 = Moldova în epoca feudalismului. Recensămintele populației Moldovei din anii 1772-1773 și 1774. Vol. VII, partea II. Academia de Științe a Republicii Moldovenești, Institutul de Istorie. Chișinău: Editura Știința, 1975.

10. OANCĂ, Teodor. Microsisteme antroponimice românești. Craiova: Editura GRAFIX, 2016. 
11. OANCĂ, Teodor. Sociolingvistică aplicată. Cercetări de antroponimie. Craiova: Fundația Scrisului Românesc, 2001. 1936.

12. PAŞCA, Şt. Nume de persoane şi nume de animale în Ţara Oltului. București,

13. Reforma = Reforma á la Al.I. Cuza-Enciclopedia Numelor Românești [online]. Disponibil: http://jurnalul.ro/vechiul-site/old-site/suplimente/editie-de-colectie/reforma195-la-al-icuza-12789.html [citat: 25.05.2021].

14. STAHL, H. H. Sistemul onomastic drăgușan. Regula „,gineririi pe curte”. În: Arhiva pentru știința și reforma socială, 1934, XII, p. 83-95.

15. TOMESCU, Domnița. Numele de persoană la români. Perspectivă istorică. București: Editura Univers Enciclopedic, 2001.

16. VULCĂNESCU, Romulus. Etnologia juridică. București, 1970.

17. ЧИЧАГОВ, В. К. Из истории русских имен, отчеств и фамилий. Moscova, 1959.

Notă: Articolul a fost realizat în cadrul proiectului de cercetare 20.80009.1606.01 Valorificarea științifică a patrimoniului lingvistic național în contextul integrării europene, Institutul de Filologie Română „B. P.-Hasdeu” al MEC. 